\title{
Pedagogical Practices of English Language Lessons in Malaysian Primary Schools: A Discourse Analysis
}

\author{
Rosniah Mustaffa \\ Universiti Kebangsaan, Malaysia \\ Email: rosniah@ukm.my \\ Idris Aman \\ Universiti Kebangsaan, Malaysia \\ Email: idrisa@ukm.my \\ Teo Kok Seong \\ Universiti Kebangsaan, Malaysia \\ Email: teokok@ukm.my \\ Noorizah Mohd Noor \\ Universiti Kebangsaan, Malaysia \\ Email: izah@ukm.my
}

\begin{abstract}
Discourse analysis as a sub-discipline of linguistics is useful in understanding the teaching and learning process and practices of a language. In line with that, this article applies discourse analysis framework in discussing the classroom pedagogical discourse practices of English language lessons at primary school level in Malaysia. The discussion is based on three case studies conducted in the state of Melaka. The pedagogical discourse in the classrooms was observed, audio recorded and later transcribed and analysed. The pedagogical discourse analysed focuses on the teachers' and students' practices. Among the teachers' practices identified were questioning, accepting and explaining where as the students' practices were answering and listening. These pedagogical practices are discussed in relation to their types, place of occurrences in the discourse and their related examples. The discussion hopes to give details on how linguistics, especially discourse analysis, benefits in language pedagogy and at the same time, enlightens the practices of English language lessons in the classrooms.
\end{abstract}

Index Terms - discourse practice, pedagogical discourse, English language, primary school

\section{INTRODUCTION}

Discourse analysis has to do with analyzing the relationship among language and the contexts in which it is used. It is also being applied in various researches such as in applied linguistics, and second language learning and teaching. As such, discourse analysts investigate language in use: all types of written texts and spoken data, from conversation to highly institutionalized types of talk. For teachers, a more accurate picture of natural discourse, can put them in a better position to assess the teaching material, what transpires in the classroom, and the end products of their teaching, either in the form of spoken or written output (McCarthy, 1991).

Analysis of classroom discourse is useful when examining the effectiveness of teaching methods and the types of student-teacher interaction (Richards, Platt, \& Platt, 1992) Classroom discourse refers to the type of language use that is found in classroom situations. This student-teacher discourse is also referred to as pedagogic discourse, and it is different in form and function from language used in other situations due to the distinct social roles of students, teachers and the activities they are engaged in (Richards et. al., 1992; Rosniah \& Idris, 2005). According to Walsh (2006), the communication patterns found in language classrooms are different from those found in content-based subjects. Communication is distinctive because the linguistic forms utilized are often the aim of a lesson and the means of achieving those aims.

In the L2 classroom, it is common that teacher controls both the content and the procedure of the learning-process. According to Cazden (in Walsh, 2006) some of the features of L2 classroom are: teachers control the topic of discussion; teachers control who can participate and when; students take their cues from teachers; role relationships among teachers and learners are lopsided; teachers are responsible for managing the interaction which occurs; teachers talk more. Any L2 lesson can be perceived as a dynamic and complex series of interrelated contexts, in which interaction is essential to 
teaching and learning. Class-based L2 learning is often improved when teachers have a detailed understanding of the relationship between teacher talk, interaction and learning opportunity (Walsh, 2006).

This paper applies discourse analysis framework in discussing the classroom pedagogical discourse practices of English as a second language lessons at primary school level in Malaysia. The pedagogical discourse in the classrooms was observed, audio recorded, transcribed and later analysed. The aims were to identify the teachers' and students' practices in the classrooms.

\section{DATA}

The data collected for this paper were through case studies of three classroom discourses of three teachers teaching Year 4 and 5 pupils in city of Melaka. The first teacher [text 1] was a female teacher who had a diploma. She had been teaching English for 13 years and the topic of her standard 5 lesson was World of Stories (The Golden Touch). The second teacher [text 2] was also female with a certificate in teaching Tamil language and had been teaching English for 2 years. Her standard 4 lesson for that day was using a letter (for comprehension and grammar). The final teacher [text 3 ] was a male teacher who also had a certificate in teaching English. He had been teaching English for 28 years and his standard 5 lesson for this study was World of Stories (Mat Janim and the Oil). Each class lesson lasted for an hour and as such, the total length of the discourse was 3 hours. Three classroom discourses were chosen because each discourse contains 1055, 1329, 1218 utterances respectively [a total of 3602 utterances]. The discourse was collected through direct audio recording during the lessons. The whole process took place in April 2009. Recordings were transcribed into texts and sort into moves and utterances. To easily manage the analysis, each utterance is given a number as shown below.

$\begin{array}{lll}\text { (1) } & & \\ \text { Particapants } & \text { Move } & \text { Utterances } \\ \text { T (Teacher): } & {[712]} & \text { What (do) you call this? } \\ \text { P ( Pupil ): } & {[713]} & \text { Eat } \\ \text { T: } & {[714]} & \text { Aa..eat } \\ & {[715]} & \text { Ate } \\ & {[716]} & \text { It's past tense of? } \\ \text { P: } & {[717]} & \text { Food } \\ \text { T } & {[718]} & \text { No }\end{array}$

Speech Functions
[Questioning]
[Answering]
[Repeating]
[Correcting]
[Questioning]
[Answering]
[Rejection]

(Source Text 2)

\section{Pedagogical Practices}

Practices in this paper refer to the utterances as functional units in communication. Searle (1981) termed this as speech acts and Fairclough (1982), as speech functions. According to Searle (1981) there are 5 main speech acts or functions. They are 1. Commissive, 2. Declarative, 3. Directive, 4. Expressive, 5. Representative which can be detailed further, such as, a commissive can be a promise or threat; a declarative can be a command or a request; and a representative can be an assertion or a report.

For example, in (1), when the teacher in Move [712] asks what you call this? The speech function is questioning. When a student responds by saying eat, the speech act is answering. In move [714] the teacher repeats aa...eat and corrects the answer in move [715] by saying ate. Again in move [716] the speech act is questioning when the teacher asks it's past tense of? And when the student responds by saying food in move [717], the speech function is answering. In move [718], the teacher says no using the speech function of rejecting the answer.

In general, the focus of classroom discourse textual analysis is on features of teacher-student interaction. Generally, interactive control in discourse is concerned with ensuring that interaction takes place effectively at specific levels of organization, for example systems of smooth distribution in turn taking, topic selection and exchange as well as question-answering (Fairclough, 1992). The discourse practices discussed in this paper are the teachers and students' practices revealed in the three texts.

\section{TEACHERS PRACTICES}

Among teachers practices founded are questioning, accepting, explaining, informing, instructing, correcting, rejecting, modeling etc. The occurrences of the practices are shown in Table 1. 
TABLE 1

TEACHERS PRACTICES

\begin{tabular}{|l|l|l|l|l|}
\hline \multicolumn{1}{|c|}{ Practices } & \multicolumn{1}{c|}{ Text 1} & \multicolumn{1}{c|}{ Text 2 } & \multicolumn{1}{c|}{ Text 3 } & Total \\
\hline Questioning & $345 / 1055$ & $440 / 1329$ & $223 / 1218$ & $1008 / 3602$ \\
\hline Informing & $60 / 1055$ & $176 / 1329$ & $87 / 1218$ & $323 / 3602$ \\
\hline Accepting & $60 / 1055$ & $79 / 1329$ & $81 / 1218$ & $220 / 3602$ \\
\hline Instructing & $51 / 1055$ & $91 / 1329$ & $58 / 1218$ & $200 / 3602$ \\
\hline T Ques \& Ans & $63 / 1055$ & $11 / 1329$ & $58 / 1218$ & $132 / 3602$ \\
\hline Modeling & $0 / 1055$ & $73 / 1329$ & $20 / 1218$ & $93 / 3602$ \\
\hline Correcting & $31 / 1055$ & $15 / 1329$ & $0 / 1218$ & $46 / 3602$ \\
\hline Praising & $5 / 1055$ & $11 / 1329$ & $14 / 1218$ & $30 / 3602$ \\
\hline Rejecting & $8 / 1055$ & $6 / 1329$ & $4 / 1218$ & $18 / 3602$ \\
\hline Translating & $13 / 1055$ & $4 / 1329$ & $0 / 1218$ & $17 / 3602$ \\
\hline Explaining & $0 / 1055$ & $8 / 1329$ & $0 / 1218$ & $8 / 3602$ \\
\hline Ignoring & $0 / 1055$ & $5 / 1329$ & $0 / 1218$ & $5 / 3602$ \\
\hline Joking & $1 / 1055$ & $1 / 1329$ & $0 / 1218$ & $2 / 3602$ \\
\hline
\end{tabular}

a) Questioning

Questioning appeared to be the most widely used speech function in these three texts. A total no of 1008/ 3602 utterances were questions. They took place 345 times in text 1, 440 in text 2 and 223 in text 3 . A prominent textual feature identified in this pedagogic discourse is the use of close-question by the teacher. Close-questions are questions that use question words such as 'right/yes-no', 'is there', 'where to', 'who' or 'what' which merely require straight answers or just confirmation. The use of open-questions that begin with questions-words such as 'why', 'how' or explain are limited. The following examples show the use of close-questions in the analysed discourse.

(2)

T: [117] Do you like gold?

P: $\quad[118]$ Yes.

$\mathrm{T}: \quad[119] \quad$ It is very expensive ah nowadays.

[120] Robbers and thieves are looking for gold.

[121] Can you wear a lot of gold, jewelleries to weddings or when you go out to or from your house?

P: $\quad[122]$ No.

(Source: Text 1)

(3)

T: [84] What passage is this?

[85] Is it a poem?

Ps: [86] No..no

T: [87] What is it?

Ps: [88] Letter..letter

(Source: Text 2)

(4)

T: [111] Its not a vase, its not a vase.

[112] It's a... Roshan?

P: [113] Jug.

T: [114] It's a jug aa.

[115] It's a...?

P: [116] Jug.

T: [117] Jug.

[118] Ok, it's a jug or a?

[119] A jug or a?

P: [120] Pot.

(Source: Text 3)

In (2), the teacher asked the close-questions in moves [117] and [121] which required the pupils to simply answer yes or no. This is the most prominent textual feature used in the pedagogic discourse identified in this study in terms of questioning techniques. Apart from yes/no answers required by the pupils, the teachers also focused on getting pupils to supply a one word answer in (3) moves [86] and [88]. In (4) too it shows that the teacher also required the pupils to produce one word answer as in moves [113], 116] and [120].

In the discourse analysed, there were instances when the teachers answered the questions themselves rather than allowing students to answer. The teachers questioned but proceeded to answer them. The teachers did not provide time for the students to think and offer their own opinions.

(5)

T: [352] Clothes aa..like shirt, dresses, pants, that is called clothing aa

[353] He gave them food and ?

[354] Clothing 
(Source: Text 2)

(6)

T: [132] How you know its oil?

[133] Again, again.

[134] Aa the title is there aa oil, oil.

[135] Oil inside the?

[136] Inside the?

[137] Pot, ok.

(Source: Text 3)

(7)

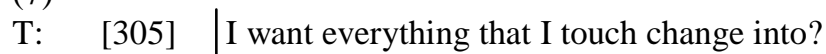

P: [306] Gold

T: [307] Gold Ok, for exx..now.

(Source: Text 1)

In (5), the teachers asked the pupils questions as can be seen in move [353] but answered it herself in move [354] without waiting for the pupils to respond. The same goes with (6) and (7), where she answered her own questions in move [137] and [307] respectively.

There are also instances where teachers use 'fishing question'. What is meant by fishing questions is when teachers provided part of the answers by mentioning the first syllable as follows.

(8)

$\begin{array}{lll}\text { T: } & {[95]} & \text { Yes, Bani? } \\ \text { S: } & {[96]} & \text { Bangle. } \\ \text { T: } & {[97]} & \text { Yes, bangle. } \\ & {[98]} & \text { Ok, bang..? } \\ \text { P: } & {[99]} & \text { Gle. } \\ \text { T: } & {[100]} & \text { Bangle. }\end{array}$

(Source: Text 1)

b) Informing

Informing is to tell something. In this study, informing is the second widely used speech function with a total of $323 / 3602$ utterances. It appeared 60 times in text 1, 176 in text 2 and 87 in text 3 . The discourse analysed in this study reflects prominently the teacher's role and teaching profession. For example, this practice happens when a teacher prefers to offer information, explanations, descriptions or answers to students rather than allowing students to discuss, analyse or summarise in order to seek for their own answers. In other words, the teacher speaks more than the student. Discourse is, thus, centred on the teacher. This practice can be seen below.

(9)

T: [836] Yesterday, I put my book on your table

[837] You don't say, yesterday I putted my book on your table

[838] Is it correct?

[839] No

[840] Ok, my mother aa

[841] Ok...aa

[842] I want to cut this cake

[843] Ok, I want to cut this cake

[844] Aaa..yesterday, I cutted the cake aa?

[845] I cut the cake also

[846] Some words aa they don't change

(Source: Text 2)

(10)

T: [968] You leave your house to go to school right?

[969] You leave your house, ok, you left your house

[970] This morning, I left my house at 7 o'clock

[971] All right?

[972] This morning, I teacher left my house at 7 o'clock

[973] That means?

[974] At 7 o'clock, I came out the house

[975] I come to school

[976] On my way to school, ok?

[977] Ok

[978] Tomorrow

[979] I'll leave home at? 


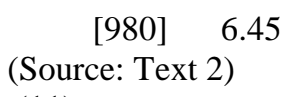

(11)

T: [194] After that I will give you a few questions retaining to the story aa.

(Source: Text 3)

(12)

T: [49] Necklace. (T put on necklace to a $S$ 's neck)

[50] Why?

[51] See ah... necklace is smaller than a chain.

[52] Short and smaller

(Source: Text 1)

All instances in (9), (10) (11) and (12) illustrate an absence of interaction between the teachers and the pupils. Teachers preferred to take the authority to inform rather than giving the opportunities for the pupils to exercise critical thinking in discussing or analyzing a particular topic. The teachers have power over the discourse and it is unevenly shared out with the pupils.

c) Acceptance

Acceptance is when teachers accept or acknowledge the pupils' answers. This could be in a form of repeating what the pupils said. 220/3602 of the total utterances are categorized as acceptance. It took place 60 times in text 1, 79 in text 2 and 81 in text 3.

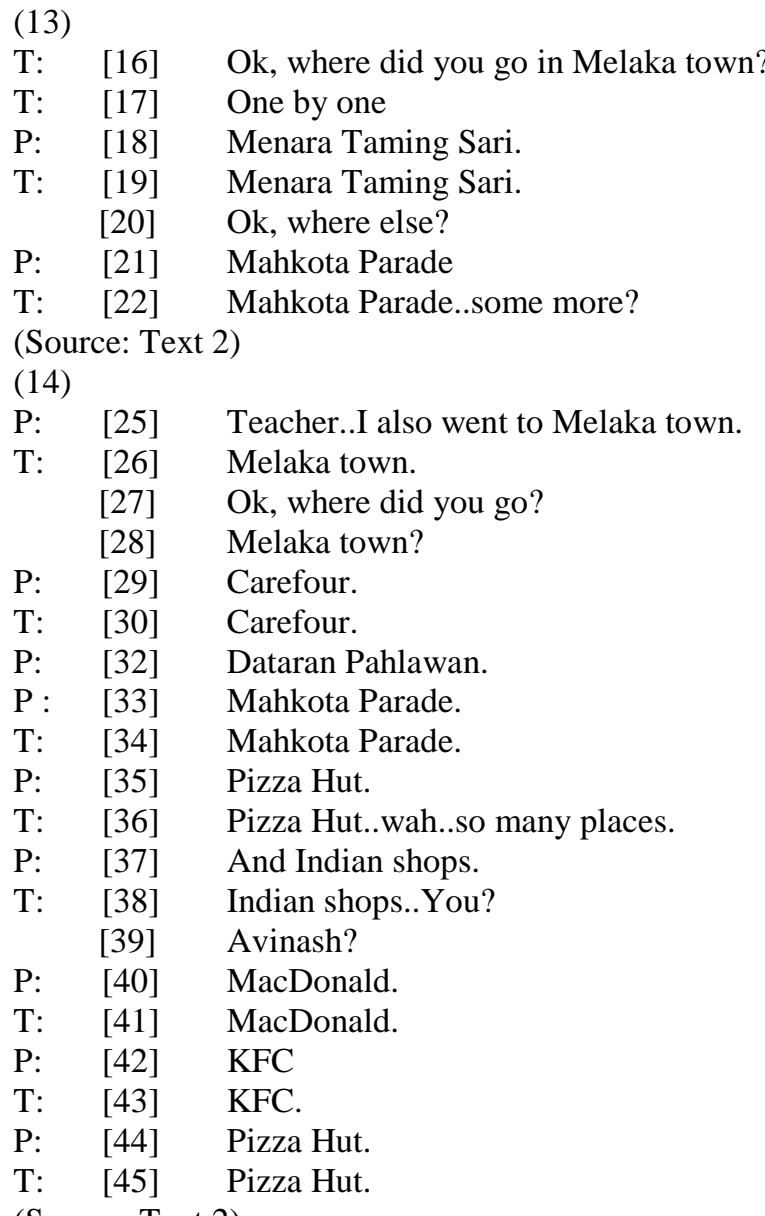

(Source: Text 2)

(15)
T: [167] Now..look at the picture there.
[168] What do you think the.
[169] How?
[170] What is the feeling of the king?
P: [171] Very happy.
T: [172] Aa..He is very?
P: [173] Happy.
T: [174] Happy
(Source: Text 1) 
(16)

T: [31] Ok, what do you think Mat Jamin is doing?

[32] What you think he's doing?

[33] Yes, Firdaus?

$\mathrm{P:}$ [34] He is dreaming.

$\mathrm{T}: \quad[35]$ He is?

P: [36] Dreaming.

$\mathrm{T}$ : [37] He is dreaming.

(Source: Text 3)

Acceptance can be seen in (13) where the teacher repeated what the pupil responded as in moves [19] and [22]. The same goes in moves [26], [30], [34], [36], [41], [43] and [45] in (14), where again the teacher repeated what the pupils answered. This scenario is repeated once more in moves [174] in (15) and finally in moves [37] in (16). Usually the teacher employed the actions of acceptance to indicate that the answers provided by the pupils were correct.

d) Instructions

Instruction is where teachers instruct the pupils to do something. In this study it is found that instruction is the fourth widely used practice. It appears 200/3602 times with 51, 91 and 58 times in texts 1, 2 and 3 respectively.

T: [187] Ok, now, you look at the story, look at the story, I let you look at the story and you read silently, aaa. [188] For 4 minutes.

(Source: Text 3)

(18)

T: [615] Once you get the paper, write down your name, and the..todays' date.

[616] Pass aaa..

[617] Ok, class..the earlier one aa, the comprehension passage, class, pay attention, Govinath!

[618] Class, this comprehension passage aa, you will need to cut and paste in your English 1, and you copy the questions and you answer them.

[619] Ok?

[620] The passage you cut and paste, then based on this, you answer the questions.

(Source: Text 2)

(19)

T: [147] Don't read the story first aa.

(Source: Text 1)

[148] Look at the picture first.

In giving instructions, usually the teachers employed this practice when it was time to do exercises or to work on a given tasks. Instructions were given to ensure the pupils understand and know what to do to complete the given tasks. Examples of this can be seen in (17) moves [187] where the teacher instructs the pupils to read the story silently and in (18), moves [618] and [620] the teacher gives instructions to the pupils what to do with the comprehension passage. In (19), the teacher instructs pupils what to do and what not to do first as depicts in moves [147] and [148].

e) Question and answer

Apart from the teachers asking questions for students to answer as mentioned earlier, there is another type of practice that the teacher employed in the classrooms. This is by asking pupils questions but not giving the thinking time for the pupils to think of the answers expected. The teachers instead answer their own posed questions and this happened 63, 11 and 58 times in texts 1,2 and 3 respectively giving a total of 132/3602 times of the total utterances.

(20)

T: $[252] \quad$ King Midas was a rich?

[253] King.

[254] Although he's rich but he loves gold.. anyone what?

[255] More

P: [256] More than.

T: [257] Golds aa..although he's rich but he want more?

[258] Golds.

(Source: Text 1)

(21)

T: [269] What a fairy always hold?

[270] A star like this, right?

[271] Tingg aa..magic?

[272] Stick aa.

[273] Always changed everything when it says 'ting' aa you change to what?

[274] Frog?

[275] Then you will jump like a? 


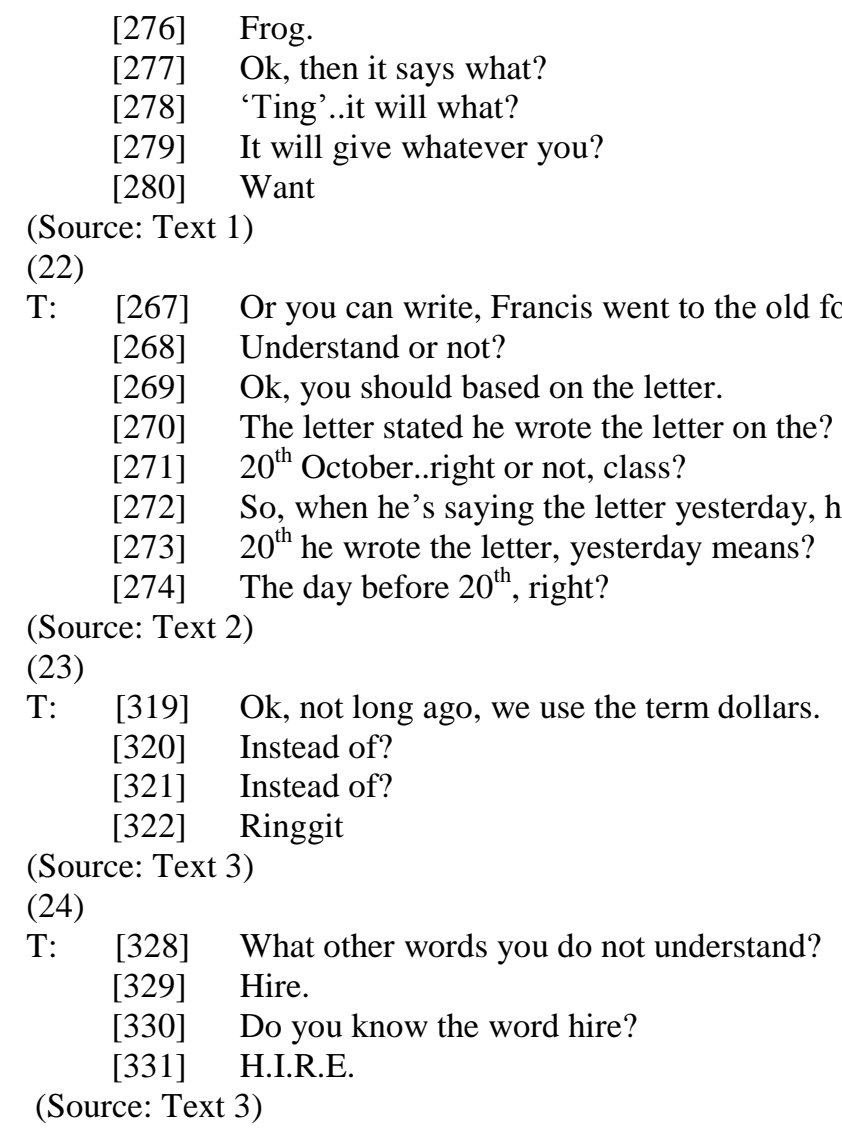

In (20), move [254] the teacher asked the pupils but answered her own question as in move [258]. This is more obvious in (21) where the teacher asked 6 questions [269], [271], [273], [275], [277], [279] but proceeded to answer them all in moves [270], [272], [274], [276], [278] and [280]. This practice is further employed in (22) where the teacher asked questions in [270] and [273] but proceeded to answer them in moves [271] and [274] respectively. The same can be seen in (23) where the teacher asked "instead of?" in move [321] and answered it herself, "Ringgit" in move [322]. This practice is repeated in (24) where the teacher asked the pupils how to spell "hire" in move [330] but she proceeded to spell it herself in move [331] without waiting for the pupils to contribute their answers.

f) Modelling

Teachers used 93/3602 of the total utterances to model the correct way of pronouncing words and also to have the pupils to repeat after them. However in text 1, no modeling was used by the teacher as compared to 73 in text 2 and 20 in text 3 .

(25)

T: [1088] I want you to go this one again aa.

[1089] Wash.

P: [1090] Wash.

T: [1091] Washed.

P: [1092] Washed.

T: [1093] Walk.

P: [1094] Walk.

T: [1095] Walked.

P: [1096] Walked.

T: [1097] Bring

P: [1098] Bring

(Source: Text 2)

(26)

T: [220] Ok, read the title $1^{\text {st }}$.

[221] Mat Jamin and the oil.

$\mathrm{P}(\mathrm{Gp} 1)[222] \quad$ Mat Jamin and the oil. (Reading the $1^{\text {st }}$ paragraph)

T: [223] Ok, very good.

[224] Can you please sit down?

[225] Ok, the $2^{\text {nd }}$ group, can you read the $2^{\text {nd }}$ paragraph?

$\mathrm{P}(\mathrm{Gp} 2)[226] \mathrm{He}$. . 
T: [227] He..

$\mathrm{P}(\mathrm{Gp} 2):[228] \mathrm{He}$ (Reading the $2^{\text {nd }}$ paragraph)

T: [229] I will sell?

$\mathrm{P}(\mathrm{Gp} 2):[230]$ (Continue reading the $2^{\text {nd }}$ paragraph)

T: $\quad[231]$ He thought.

$\mathrm{P}(\mathrm{Gp} 2):[232]$ (Continue reading the $2^{\text {nd }}$ paragraph)

(Source: Text 3)

There were many instances of modeling the correct pronunciation of words in text 2 and 3. Examples of such practices can be seen in (25) from move [1089] to [1098] where the pupils model each word the teacher says. The same with (26) where the pupils started reading the paragraph from the word or phrase modeled by the teacher as in moves [228], [230] and [232].

g) Correcting

Teachers usually use corrections in the classrooms. What was observed in the classrooms was the fact that the teachers do corrections on the spot when the pupils made mistakes. A total of 46/3602 utterances were correcting the students' pronunciation with 31 corrections done in text 1,15 in text 2 and none in text 3 as shown below.

T: $\quad[193]$ Ok.

[194] Amar read.

P: $\quad$ Reading passage

T: [195] King Midas aa..(correcting the pronunciation)

$\mathrm{P}: \quad$ Continue reading passage

T: [196] Else...anything else..(correcting the pronunciation)

P: $\quad$ Continue reading passage

T: [197] In the world. (correcting the pronunciation)

$\mathrm{P}: \quad$ Continue reading passage

(Source: Text 1)

(28)

T: [223] Princess Stefanie (correcting the pronunciation)

P: [224] Princess Stefanie (and continue reading passage)

$\mathrm{T}: \quad[225] \quad$ Begged (correcting the pronunciation)

P: [226] Begged (and continue reading passage)

T: [227] Horrible (correcting the pronunciation)

P: [228] Horrible (and continue reading passage)

$\mathrm{T}:$ [229] Lesson (correcting the pronunciation)

P: [230] Lesson (and continue reading passage)

$\mathrm{T}:$ [231] The kind fairy (correcting the pronunciation)

$\mathrm{P:}$ [232] The kind fairy (and continue reading passage)

(Source: Text 1)

(29)

T: [127] You are.. (correcting the pronunciation)

P: [128] (Continue reading passage)

$\mathrm{T}: \quad$ [129] Folks (correcting the pronunciation)

$\mathrm{P:}$ [130] (Continue reading passage)

$\mathrm{T}: \quad[131] \quad$ Folks (correcting the pronunciation)

P: [132] (Continue reading passage)

$\mathrm{T}: \quad$ [133] Knew (correcting the pronunciation)

$\mathrm{P:}$ [134] (Continue reading passage)

T: [135] We were (correcting the pronunciation)

$\mathrm{P}: \quad$ [136] (Continue reading passage)

(Source: Text 2)

In (27), the teacher corrected the pupils' pronunciation as the pupil was reading and it happened every time the pupil mispronounced the words. The same can be seen in (28) and (29) where the teachers corrected all the pronunciations made by the pupils as they did the readings.

h) Praise

Utterances which give compliments to the pupils are categorized as praising. The total number of utterances used as praise is only 30/3602 where it is used 5, 11 and 14 times in texts 1,2 and 3 respectively. Basically the words used were "very good" instead of other compliment words.

(30)

T: [145] Orphange (correcting the pronounciation)

$\mathrm{P:} \quad$ [146] (Continue reading passage) 
T: [147] Very good.

(Source: Text 2)

(31)

T: [349] How do you spell rent?

S: [350] R.E.N.T

T: [351] Yes.

[352] Very good.

(Source: Text 3)

(32)
T: [543] Sit aa?
[544] Becomes?
P: [545] Sat!
T: [546] Sat.
[547] Very good.

(Source: Text 2)

(33)

T: [62] Chain.

[63] Ok, what is this?

[64] Small thing...ah yes..

S: [65] Locket.

T: [66] Very good

(Source: Text 1)

In (30), (31), (32) and (33), the compliment "very good" appeared in moves [147], [352], [547] and [66] respectively. The teachers in all the 3 texts did not use other compliment words such as "great", "excellent" or "good". By not doing so, the pupils were not exposed to varied vocabularies in the classroom.

i) Translating

Using translation is not uncommon in language classrooms in Malaysia. Translating could happen in the pupils' mother tongue or the national language. Teachers use translation when the pupils do not understand the word in English and students use translation when they do not know to say the words in English. In total, only 17/3602 of the utterances were translation words. Specifically, text 1 used 13 translation words, texts 2 used 4, while text 3 did not use any.

(34)
T: [152] A king.
[153] How you know he is a king?
S: [154] He got a..(not clear)
S: [155] Mahkota.
T: [156] That mahkota.
[157] What you call it in English?
[158] What you call it in English?
[159] It starts with the letter C....
P: [160] Criss
T: [161] Criss aa?
[162] Crown.

(Source: Text 1)

(35)

T: [262] What is fairy?

P: [263] A small..(not clear)

T: [264] Mm?

[265] A small what?

[266] Aa?

P: [267] Pari-pari.

T: [268] Pari-pari.

[269] What a fairy always hold?

[270] A star like this, right?

(Source: Text 1)

(36)
T: [469] Gold.
[470] He said excitedly.
[471] What is excitedly?
T: [472] Dengan penuh apa? (In Malay)
P: [473] (In Tamil) 


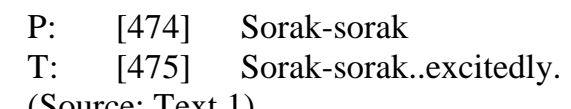

(Source: Text 1)

(37)

T: [483] Stefanie, ok.

[484] "Hello, my little Princess," said King Midas and gave her a pat.

[485] What is pat?

P: [486] Chest.

P: [487] Shoulder.

T: [488] What are you telling?

[489] What is that in Tamil?

P: [490] (In Tamil)

(Source: Text 1)

(38)

T: [103] Orphanage..Ok, what is an orphanage?

P: [104] (In Tamil).

T: [105] (In Tamil).

[106] People who don't have anybody, parent, siblings aa..sisters, brothers, nobody, any relatives..K?

[107] Its called orphanage.

[108] Orphans aa..they are orphans.

[109] Ok, what you call in Malay orphans?

P: [110] Anak..

P: $\quad[111]$ Anak yatim.

T: [112] Ok, anak yatim-piatu aa..they got nobody in this world.

(Source: Text 2)

(39)

$\begin{array}{lll}\text { T: } & {[418]} & \text { Past tense..right? } \\ & {[419]} & \text { Good. } \\ & {[420]} & \text { They are verbs. } \\ & {[421]} & \text { Verbs aa. } \\ & {[422]} & (\text { In Tamil }) . \\ & {[423]} & \text { Kata kerja. } \\ & {[424]} & \text { Verbs. }\end{array}$

(Source: Text 2)

In (34), the pupil did not know the word "crown" and resorted to saying "mahkota" in move [155]. The teacher then translated "mahkota" into "crown" in move [162]. In (35), the pupil could not describe the meaning of the word "fairy" and said the equivalent word in Malay, "pari-pari" in move [267]. Besides resorting to translate words intro Malay, the pupil in (36) also used Tamil (this is a Tamil school) in move [473] to explain the meaning of "excitedly" besides the Malay word "sorak-sorak" in move [474]. In (37), the teacher asked the pupil the meaning of the word "pat" in Tamil as can be seen in move [489] and the pupil answered in Tamil in move [490]. In (38), the pupil answered in Tamil in giving explanation of the word "orphanage" then the teacher explained the meaning again in English [106]. She also asked the pupils the meaning of "orphans" in Malay instead of in English in move [109] and the pupil answered in Malay in moves [110] and [111]. Interestingly in (39) the teacher explained what verbs are in Tamil [422] and in Malay [423].

1) Jokes

Although jokes and humor in the classrooms can make the pupils relax, they are used very rarely in the classrooms. It takes the teachers' wittiness to spontaneously create jokes related to the lessons such as the ones below. Only $2 / 3602$ utterances are considered as jokes with 1 in text 1,1 in text 2 and none in text 3 .

(40)

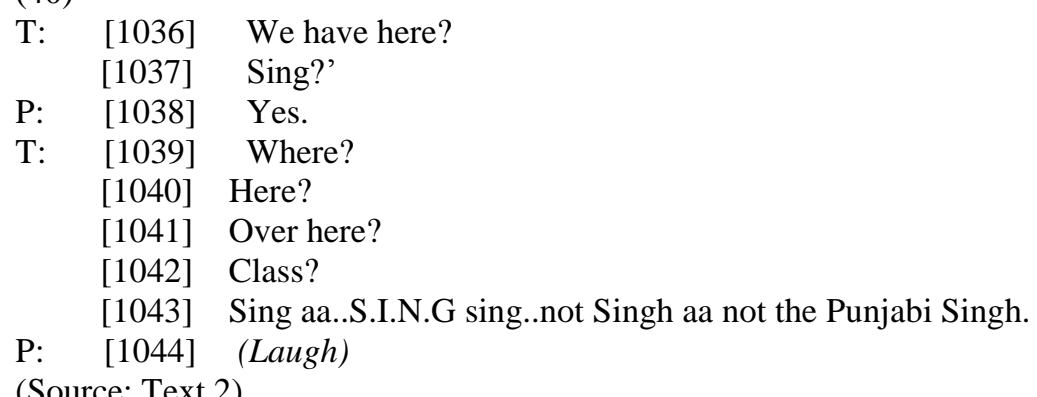

(41) 
T: [373] Waa, he wants an...?

P: [374] I want an aeroplane.

T: [375] Aeroplane.

[376] Ok. as a fairy, I'll give him a toy aeroplane.

[377] Next time aa...

(Source: Text 1)

There were only 2 jokes that emerged in the 3 lessons. One was in (40) where the teacher said "Sing aa..S.I.N.G sing..not Singh aa not the Punjabi Singh" in move [1044] which created laughter among the pupils. The other was in (41) where the teacher said in move [376] "Ok. As a fairy, I'll give him a toy aeroplane" and moved on to say in move [377] "Next time aa..."

\section{PUPILS PRACTICES}

As for the pupils' practices, the common ones are answering, repeating and questioning. Correcting was also detected in this study, which is rare in Malaysian classrooms. The findings are shown in Table 2.

TABLE 2

STUDENT PRACTICES

\begin{tabular}{|c|c|c|c|c|}
\hline \multicolumn{1}{|c|}{ STUDENT PRACTICES } \\
\hline Practices & Text 1 & Text 2 & Text 3 & Total \\
\hline Answering & $202 / 1055$ & $199 / 1329$ & $156 / 1218$ & $557 / 3602$ \\
\hline Repeating & $29 / 1055$ & $73 / 1329$ & $0 / 1218$ & $102 / 3602$ \\
\hline Questioning & $1 / 1055$ & $4 / 1329$ & $7 / 1218$ & $12 / 3602$ \\
\hline Correcting T & $0 / 1055$ & $1 / 1329$ & $0 / 1218$ & $1 / 3602$ \\
\hline
\end{tabular}

a) Answering

As for the pupils' practices, basically their main role in the classrooms were answering the teachers' questions with a total of 557/3602 utterances. In text 1, 202 of the utterances were the pupils answering the teachers' questions, 199 in text 2 and 156 in text 3 . Answers were basically one word answers which were very straight forward and do not require the pupils to think creatively.

(42)

T: [78] Louder ah, you must speak loud.

[79] What is this?

[80] What is this?

P: [81] Hand... (not clear)

T: [82] Hand ah... hand... so?

P \& T: [83] (Not clear)

T: [84] Cincin ah?

P: [85] Cincin.

$\mathrm{T}: \quad[86] \quad$ Ok. What is this?

P: [87] Ring.

(Source: Text 1)

(43)

T: [138] Ok ah, what is the title of the story?

P: [139] The Golden Touch.

T: [140] Again?

P: [141] The Golden Touch.

T: [142] The Golden?

P: $\quad$ [143] $\quad$ Touch.

T: $\quad$ [144] Touch

(Source: Text 1)

(44)

T: [474] Everyday Meena and Getha come to school by bus.

[475] Yesterday Meena and Getha?

P: [476] went!

T: [477] Come becomes?

P: [478] Came!

$\mathrm{T}:$ [479] Came..came to school by?

[480] Bus.

(Source: Text 2)

(45)

T: [105] Yes, anybody?

[106] Isyazwan, what is that? 


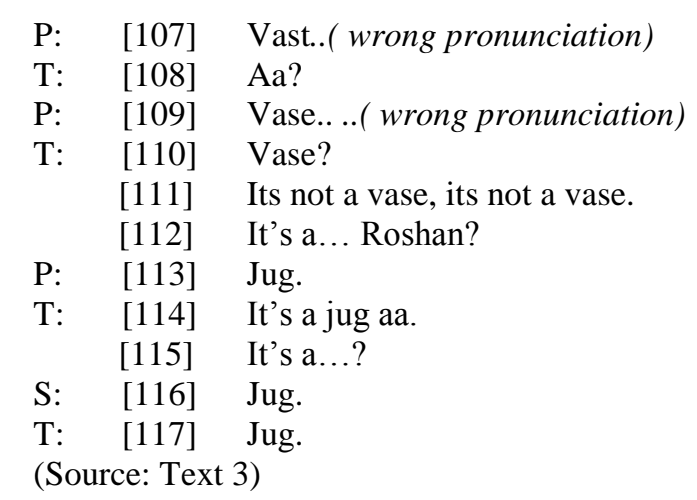

In answering the teachers' questions, most answers were one word answer as can be seen in (42) moves [81] and [87]. The same goes in (43) move [143], in (44) moves [476] and [478]. In (45), the one word answers can be seen in moves [107], [113], and [116].

b) Repeating

There are instances where teachers modeled the correct pronunciation of the words and required the pupils to repeat after them. This practice is revealed in 102/3602 of the utterances with 29 utterances in text 1, 73 in text 2 and none in text 3.

$\begin{array}{lll}\text { (46) } & & \\ \text { T: } & {[257]} & \text { Old folks' home } \\ \text { Ps: } & {[258]} & \text { Old folks' home } \\ \text { T: } & {[259]} & \text { On the } \\ \text { Ps: } & {[260]} & \text { On the } \\ \text { T: } & {[261]} & 19^{\text {th }} \text { of } \\ \text { Ps: } & {[262]} & 19^{\text {th } \text { of }} \\ \text { T: } & {[263]} & \text { October } \\ \text { Ps: } & {[264]} & \text { October } \\ \text { T: } & {[265]} & 2007 \\ \text { Ps: } & {[266]} & 2007\end{array}$

(Source: Text 2)

(47)

T: [1089] Wash.

P: [1090] Wash.

T: [1091] Washed.

P: [1092] Washed.

T: [1093] Walk.

P: [1094] Walk.

T: [1095] Walked.

P: [1096] Walked.

(Source: Text 2)

(48)

T: [573] Ok, read the first one..(Reading the dialogue and $P$ follow)

[574] Read la.. (Reading the dialogue and $P$ follow)

[575] Ok, how you read emotionally?

[576] How you read? (Reading the dialogue and $P$ follow)

[577] Ok, second one. (Reading the dialogue and $P$ follow)

(Source: Text 1)

In (46), it can be seen that the pupils repeated every word the teacher said from moves [257] to [266] and from moves [1089] to [1096] in (47). As for (48), the pupils read after the teacher in moves [573], [574] [576] and [577].

c) Questioning

Questioning here refers to utterances which are made by the pupils in asking the teachers. Only 12/3602 utterances were questions made by the pupils. 1 from text 1,4 from text 2, 7 from text 3 .

(49)

T: [594] Write beside here.

[595] Eyy..Here the story.

P: [596] Match?

T: [597] Aaa.

[598] Match to the... no, no you don't have to draw lines.. just number.

[699] Just put the number aa.. put on the day. 
(Source: Text 1)

(50)

T: [700] Certain words aa.they don't change.

[701] Any change from present tense to past tense.

[702] Some, the pronounciation is changes but the spelling is the same.

P: [703] Teacher, cut?

T: [704] Cut never change.

(Source: Text 2)

(51)

T: [374] What other words you don't understand?

[375] Yes?

[376] Look at the look at the story again, any words you don't understand?

[377] You can put up your hands.

[378] Yes?

S: [379] Soon. (wrong pronounciation)

[380] S.O.O.N.

T: [381] S?

S: [382] O.O.N.

T: [383] S.O.O.N.

[384] Soon.

[385] Ok, S.O.O.N.

(Source: Text 3)

In (49), the pupil in move [596] asked the teacher for confirmation as to what they were supposed to do and the teacher affirmed it in move [597]. In move [703], we can see that the pupil questioned the teacher the past tense form of the word 'cut' where the teacher in returned explained in move [704] that the spelling of 'cut' does not change. Another example is in (51) where the teacher asked if there were words that the pupils did not understand and the pupil in move [379] asked the teacher the meaning of the word 'soon'.

d) Correcting Teacher

It is a very rare occasion where we find a pupil brave enough to correct a teacher in a classroom. There is one instance where a pupil corrected a teacher as shown below. It happened in text 2 .

$(52)$

P: [287] Teacher!

T: [288] Yes?

P: [289] Francis..Live..Melaka..teacher.

T: [290] Yes?

P: [291] Number 1.

T: [292] Owh..sorry, class..number 1 aa.. where does Francis lives?

[293] Where does Francis lives?

Ps: [294] Francis lives in Kuala Lumpur.

T: [295] Aa..who is staying in Kuala Lumpur?

Ps: [296] Kim Seng.

Ps: [297] Kim Seng.

T: [298] Kim Seng.

[299] The letter was written by Francis, so, Francis lives in?

Ps: [300] Jalan Tamarind..

T: [301] Ok..Jalan Tamarind, Melaka.

[302] Ok, Francis lives in Melaka.

[302] Who lives in Kuala Lumpur?

Ps: [303] Kim Seng.

(Source: Text 2)

Here, one pupil realized that the teacher gave the wrong answer for No. 1 and the pupil corrected the teacher in move [289]. The teacher then re-examined the content of the letter to figure out who wrote it and realized that the pupil was right. This happened throughout moves [292] until [303].

\section{CONCLUSION}

The analysis depicts the real situations in the classrooms. From the teachers and pupils practices observed and analysed in English language classrooms, the teaching and learning of English language in Malaysia is still teacher oriented where teachers used mostly questioning, informing, instructing, accepting, modelling and correcting. Students were only given the opportunities to answer one word answer and repeat after the teacher. Nevertheless, there are still 
rooms for improvement on some of the ways in which teachers normally carry out their lessons, giving more opportunity for the pupils in practicing using the language in more meaningful ways.

\section{ACKNOWLEDGEMENT}

This paper is based on UKM-GUP-JKKBG-08-08-032 research project. We would like to express our gratitude to the Ministry of Education and the schools involved for their cooperation in this study.

\section{REFERENCES}

[1] Fairclough, N. (1992). Discourse and social change. Cambridge: Polity Press.

[2] McCarthy, M. (1991). Discourse analysis for language teachers. Cambridge: Cambridge University Press.

[3] Richards, I.C., Platt, J. \& Platt, H. (1992). Longman dictionary of language teaching and applied linguistics. Essex: Longman.

[4] Rosniah Mustaffa \& Idris Aman. (2005). A Critical Discourse Analysis of the Teaching and Learning of L1 in Malaysia. Proceedings of the International Conference on Critical Discourse Analysis: Theory into Research. Editor: Thao Le. University of Tasmania. November. Pp. 502-517.

[5] Searle, J. R. (1981). Speech acts. London: Cambridge University Press.

[6] Walsh, S. (2006). Investigating classroom discourse. London: Routledge.

Rosniah Mustaffa, Ph.D (Malaya) is Associate Professor at the School of Language Studies and Linguistics, Faculty of Social Sciences and Humanities, Universiti Kebangsaan Malaysia.

Idris Aman, Ph.D (Malaya) is Associate Professor at the School of Language Studies and Linguistics, Faculty of Social Sciences and Humanities, Universiti Kebangsaan Malaysia.

Teo Kok Seong, Ph.D (Berkeley, California) is Professor at The Institute of Malay World and Civilization (ATMA), Universiti Kebangsaan Malaysia.

Noorizah Mohd Noor, Ph.D (Malaya) is Senior Lecturer at the School of Language Studies and Linguistics, Faculty of Social Sciences and Humanities, Universiti Kebangsaan Malaysia. 